\title{
Towards an Efficient Information Systems Development Process and Management: A Review of Challenges and Proposed Strategies
}

\author{
Achimugu Philip ${ }^{1}$, Babajide Afolabi $^{2}$, Oluwaranti Adeniran', Oluwagbemi Oluwatolani', \\ Gambo Ishaya ${ }^{2}$ \\ ${ }^{1}$ Computer Science Department, Lead City University, Ibadan, Nigeria; ${ }^{2}$ Department of Computer Science and Engineering, Obafemi \\ Awolowo University, Ile-Ife, Nigeria. \\ Email: \{check4philo, tolapeace, igpeni\}@yahoo.com, \{bafox, aranti\}@oauife.edu.ng
}

Received July 31 ${ }^{\text {st }}$, 2010; revised August 26 ${ }^{\text {th }}$, 2010; accepted August $31^{\text {st }}, 2010$.

\begin{abstract}
Before Information Systems are developed, they must have undergone a process called Systems Development Life Cycle (SDLC) using appropriate methodology. The SDLC consists of phases varying from author to author. However, an information systems project can only be successful with intense interaction amongst project manager, systems analyst, system designers and the end users. Viewed from the project manager's perspective, the SDLC lacks the essence of project management activities. Similarly, end users involvement is not clearly specified. The main aim of this paper is to propose a framework for information systems management and development process which accommodates the views of the different participants. Furthermore, the paper sharpens the concept of conventional SDLC, on the basis of the proposed framework. In addition, tools and methods that are appropriate for the implementation of the framework are herein discussed.
\end{abstract}

Keywords: SDLC, Information Systems, Framework, Project Management, Development, End Users

\section{Introduction}

The early applications of computers were implemented without the aid of any explicit Information Systems (IS) development methodology and appropriate management techniques. In these early days, the emphasis of computer applications was towards programming. This meant that system developers were technically trained but were not necessarily good communicators. This often meant that the needs of the users in the application area were not well established, with the consequence that the IS design was frequently inappropriate for the application. Few programmers would follow any formal methodology; in most cases, they use rule-of-thumb and rely on experience [1].

Estimating the date on which the system will be operational was difficult and applications were frequently behind schedule. Programmers might spend a very large proportion of their time on correcting and enhancing the applications which were operational. Typically, a user will come to the programmer asking for a new report or modification of one that was already supplied. Often, these changes had undesirable effects on other parts of the system, which also had to be corrected. This vicious circle will continue, causing frustration to both programmers and users. As computers increased rapidly in number and management was demanding more appropriate systems for their expensive outlay, the situation could not continue. There were three main changes [2]:

1) The first was a growing appreciation of the part of the development of the system that concerns analysis and design and therefore, the role of the system analyst as well as that of the programmer;

2) The second was realizations that as organizations were growing in size and complexity; it was desirable to move away from one-off solutions towards a more integrated approach;

3) The third was an appreciation of the desirability of an accepted methodology for the development of information systems.

Organizations today are much more concerned about the effects of competition than they were in the past; 
therefore, no organization would like to stand the risk of being overtaken by other competitors on the same playing ground with equal opportunities. Organizations that acquire prompt delivery of information system projects and posses efficient management skills will always be at the fore front of this global digital drive which commands profits for organizations and good quality of services for users and customers. Although, traditional uses of information technology still exist, new information systems development has become one of the most important weapons for organizations to gain competitive advantage. New application development is the most vigorous for those organizations that recognize information as a resource for achieving their strategic goals.

Existing literature provides some formal methods and management models for information systems development which cannot explain all the tasks that must be performed by the diverse group of people that are involved in the development process of information systems. For instance, the waterfall model in isolation cannot fully explain the perspective of the project manager, same goes to the capability maturity model and hosts of others. The primary management goal is to build a working information system under a planned budget and schedule. The activities such as planning, organizing, staffing, leading and controlling are of particular importance in managerial activities [3].

The main aim of this paper is to propose a framework for an efficient information systems development process and management that will enable information system projects to be promptly and successfully completed through the integrated efforts and view of the project manager and end users, along with other project staff members such as system analysts, developers, programmers and maintenance programmers.

\section{Information Systems Management and Development Process}

New information system development typically starts with a temporary organizational structure called project team. Typically, a project team consists of a project manager, system analyst, programmers, etc. A project manager, usually a senior system analyst in the organization has the responsibility of the entire project. The project members must intensively interact with users. For prototyping projects, the team must include the users. The importance of users' participation in information systems development is highlighted by an increasing use of new software productivity tools such as Computer Aided Software Engineering (CASE) tools. These tools enable users to be actively involved in the system devel- opment process, and to improve the chance that the final system will be adopted by users. It therefore must be emphasized that information systems can be successfully completed only with intense interactions among project participants. A critical analysis of information system management and development process suggest that its different aspects should be highlighted according to different participants. Therefore, the management and development process is divided into three levels, each of which corresponds to a type of participant. A set of activities that should be performed at each level is defined as a schema. The hierarchical architecture consists of thee schemas: manager's, actor's and user's schemas.

\subsection{Manager's Schema}

This schema represents a set of activities performed by a project manager. Proper project management is a necessary ingredient for successful project implementation. The project manager must effectively use the management tools for proper project management. The project management goal must be achieved through appropriate management activities. These managerial activities are categorized into five functions: planning, organizing, staffing, leading and controlling. Each activity of a manager can be readily placed within one of these five management functions. This perspective is what a project manager must conceive during the course of project management. This level corresponds to manager's schema. The logical view of information systems conceived by each individual actor must be mapped into the manager's schema. In other words, each activity performed by actors must confirm to the manager's goal. This mapping also can ameliorate communication barriers among project developers and manager.

\subsection{Actor's Schema}

This schema represents the activities assigned to system analyst, programmers and maintenance programmers. These developers, except for managers will be referred to as actors. The primary goal of actors must be to meet user's requirement as spelt out in the Software Requirement Specification (SRS) document. The actor's goal is to develop the information system that will be successfully adopted by end users. This schema explicitly encompasses the SDLC, from system planning to maintenance. A set of activities at this level is referred to as actor's schema.

\subsection{User's Schema}

This schema represents the activities performed by end users; it must aid actors to develop a successful system. 
The user's schema represents a set of activities by end users. The main purpose of this schema is to identify and describe the tasks that are required of users to guarantee the success of the project. Users and actors often have a many-to-many relationship. In other words, one actor may work with several users and one user may work with several actors. The user's schema must be mapped into the requirements.

The hierarchy is useful for describing a concept for information systems management and development. Any information system project can neatly be matched into the prototype framework. The primary advantages of the three schema hierarchy are highlighted as follows:

First, the information systems development process can be better understood by project participants. Better understanding of other participant's perspective of the development process results in improved communication among project members along with users. The communication gap has been the most significant cause of system failures. Secondly, the hierarchy views the entire development process as an integrated entity. It integrates different views and thus reduces the task duplication. Furthermore, the hierarchy sharpens the idea of how the information requirements can be mapped into strategic goal for the information systems in an organization. It also presents mapping between users and actors. This mapping is significant especially for prototyping approach.

The three schema hierarchy can accommodate both the top-down view and the bottom-up view of the systems management and development activities. Obviously, systems management and development consist of both management and development processes. Typically, the management process in isolation starts with an activity by a manger. The activities performed by a manager must be mapped into activities with actors and then activities by users. This transitive specialization corresponds to a top-down view for systems development. In contrast, to management process, the development process starts with the activities performed by the users. The activity performed by the users must be triggered by users' requirements. The activities are mapped into activities by actors and then activities by managers. This specialization corresponds to a bottom-up view for system development. The hierarchy also highlights the user participation in the project. It is of particular importance for prototyping approaches. The role of SDLC in prototyping is sharpened by a specific description of user's involvement. This improvement is of particular interest because the traditional SDLC discourages more effective approaches like prototyping.

The aim of presenting a three schema hierarchy is to provide a framework in which each individual project participant can better conceive the overall view of the information systems project. Furthermore, each project participant can better perform his task so that the system can be finally accepted within the organization.

\section{Conceptual Framework for Enhanced Information Systems Development and Management Process}

From a systems analyst's perspective, the SDLC perfectly illustrates the systems development process. Typically, the SDLC consist of several phases. Information systems literature has produced a variety of SDLC phase's nicknames. The actual name of the SDLC phases may vary depending on authors. They generally differ in how many phases are recognized. However, the current SDLC concept displays some shortcomings. For instance, the life cycle concept aggravates the communication gap between end users and actors. It also fails to specify the interdependency between a manager and the actors. In order to address these problems, we have incorporated the system management process into the enhance ISD and management framework we have proposed in this report. The framework is presented below:

The outset situation of the IS investment project consists of the organizational norms and values, project specific contextual factors and the resources given to the project. The actual outcomes of the IS investment project are produced in conjunction with the business development process, the IS development and procurement processes. The outcomes of the IS project are defined by the success of the system with respect to the investment perspective, the success of the IS project implementation and the success of the desired IS functionality. The basic idea in our conceptual framework, presented in Figure 1, is the inclusion and integration of all IS participants involved in its development and management processes throughout the IS product life cycle. The components of the framework are discussed in more details in the following.

\subsection{Outset Situation}

Organizations operate and survive through organizationally accepted rules that are justified by goals or a hierarchical goal system. Within organizations, there are individual goals, objectives, desires, wishes, intentions, etc, as well as organizational goals, objectives, missions, etc. [4]. As pointed out by [5], any strategic investment process employs individual and organizational values and preferences, goals and objectives as an input. At best, undertaking this task will help the project team members to understand the organization's processes, problems and 


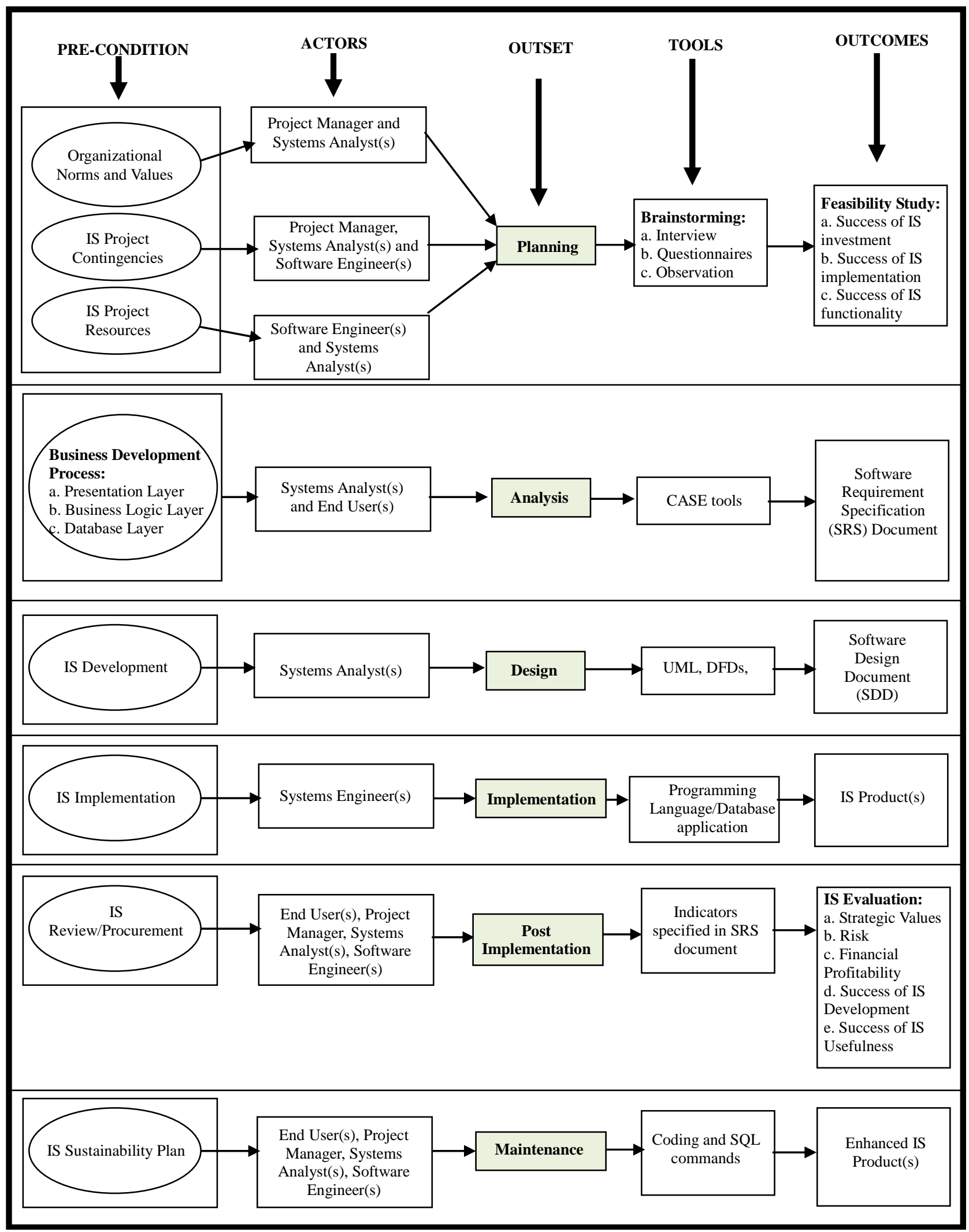

Figure 1. Conceptual framework for enhanced information systems development and management process. 
opportunities, thus facilitating organizational learning.

\subsection{Project Contingencies}

An information system can, on the one hand, be a small application supporting only one single activity, but on the other hand, it can be a wider system supporting the whole company, or it can even be an inter-organizational system. There is one additional type of information system that deserves special attention, which are infrastructure investments. Infrastructure investments are of high importance because they create the platform on which future applications can be built. Moreover, why the information system is actually built, depends on several factors. In some situations a company may be forced to build a new information system, e.g. because of legislation changes. Additionally, the senior management may perceive that the system needs to be built, for example, to support a business strategy. Finally, the arguments for building the system can be from the expected and clear quantitative or qualitative benefits from the investment perspective.

The nature of the investment varies according to the novelty of the system. An investment can deal with improving an existing system, replacing an old system or developing an entirely new system. Reference [6] asserts that the nature of the investment differs according to how common this type of system is in the field of industry where the company operates. For example, investment in a routine system is different from an investment in an innovative system. All these must be taken into cognizance for an effective and efficient IS development and management process at the planning stage of the life cycle.

\subsection{IS Project Resources}

Both the material and the immaterial resources are crucial while developing information systems. The integrating role of the major actors as depicted in figure 1 includes detecting possible problems and as a result of evaluation it may be noticed, for example, that the project needs more system development resources.

\subsection{Business Development Process}

As information technology can make alternative operational designs possible, it in many cases plays a central role when developing the company's business strategy that is to be embedded in the IS product in order to improve organizational processes. Furthermore, IT enables new kinds of flexible inter-organizational arrangements. Moreover, information technology can support the development of new business, or new products and services. Thus, IS projects are often connected to larger strategic business development programs and the role of IS actors under this category is to ensure that the IS project would deliver the required technological capabilities for achieving the strategic business objectives. The degree that an IS project is involved in business development can range from a system that supports the current business strategy to a system that creates competitive advantages and new business opportunities to the company. An information system investment is in many cases an important part of a business process re-engineering project. The actual aim of the system investment would be cutting costs, improving products or services, or serving a certain customer group better.

\subsection{IS Development Process}

In the ever-changing business environment, it is very important to be aware of the possible changes that may, in some situations, affect the underlying assumptions that the investment is based on. Thus, it would be essential to conduct evaluation regularly during the development process. According to [3], there are basically three development strategies: to use a system life cycle -based methodology, an iterative methodology (e.g. prototyping) or a mixed methodology. The choice of the development method obviously affects the way evaluation is conducted; for example, prototyping can be considered an evaluation methodology in itself. There are several factors that affect the risk of the development process. First, the risks would be decreased if parts of existing systems or existing knowledge can be exploited in system development [3]. Secondly, there are some factors related to project management; the knowledge and skills of the system developers and the representatives of the users affect the risks of the IS development project; the cooperation within the project group and between the project group and the users must be active in order to minimize the project risks; and the risks of the project could be decreased by using formal project management and control methods [3].

In summary, reference [1] presented the following factors affecting the risk of a system development project: 1) Technological newness; 2) Application size; 3) Expertise of development team and users; 4) Application complexity; 5) Organizational environment (e.g. conflicts, role definitions).

\subsection{IS Procurement Process}

Basically, an information system may be developed in-house (custom written), it may be developed by a software vendor, or the company may purchase a software package (commercial off-the-shelf). Reference [7] described two recent trends in information resource ac- 
quisition: firstly, the process has changed from an internal to market-oriented; second, there is a more distinct focus on business processes. When using an outside vendor to develop the system, evaluation procedures should be explicitly designed for contracting purposes, since all individuals acting as clients for IS projects may not be knowledgeable about the technology related issues. While IS often plays a central role in developing new business processes, the choice of the IS procurement strategy is critical for company operations. For different kinds of systems different kinds of resources are needed and consequently different procurement strategies are applicable. According to the procurement principles for choosing the efficient procurement strategy, presented by [6], routine systems should be implemented by acquiring software packages from implementers, while standard applications require software contracting by analysts and possibly other outside resources for implementation, and speculative investments are best left for internal development by innovators.

\subsection{IS Evaluation Process}

Reference [8] argued that, the evaluation process should identify and control the critical areas of an IS project. Before selecting the evaluation criteria and methods and deciding who would be involved in the evaluation, it is important to identify all the relevant interest groups for the IS project. A covering set of evaluation criteria should be used to make sure that all dimensions of the IS endeavour are taken into account and assessed. The IS evaluation process must be integrated into business development process, the IS development process, and the IS procurement process.

Reference [9] suggested a three-step process for IS evaluation: 1) Intangible benefits evaluation, 2) IS investment risk analysis, and 3) Tangible benefits evaluation. The steps should be taken in this order, i.e., intangible benefits and risks should be evaluated prior to evaluating the tangible benefits. In our framework, the order of the evaluation categories "strategic value", "risks" and "financial profitability" reflects this suggestion. The "success of IS development" category is placed prior to the "success of IS usefulness" since the usefulness can only be observed after the IS has been used for a while. Ideally, IS evaluation would cover all the above categories, but, however, it is expected that the focus of evaluation is different depending on who conducts the evaluation and where the initiative for the evaluation comes from. Reference [5] stated that the focus of evaluation changes according to the organizational interests, which may be on a number of levels, e.g. costs and benefits, organization's competitive position or industrial relations.
We argue, however, that whether the organization's interests are taken into account appropriately depends on the knowledge and skills of the evaluator. Thus, the senior management should carefully consider who should be involved in the evaluation. The result of the evaluation should be delivered to each person related to the project so that the information received from the evaluation can be employed in the decision making phase. Most likely, the decision itself would be continuing with the investment (maybe after some minor changes), changing the specifications, range or implementation method of the system, or 'freezing' the project. In addition, the changes might include e.g. schedule changes; reorganization of the project (e.g. project management can be changed); or vendor changes. The reasons for these changes may be obvious mistakes, unexpected problems, a new experience about the project that changes the idea of the right course of action, or changes in the company's environment, that are beyond the company's control.

\subsection{Outcomes}

The outcomes of an IS project are identified as the success of 1) IS implementation, 2) IS investment, and 3) IS functionality. IS Evaluation should not work only as a justification mechanism but as a tool for experience learning. During the IS development process, feedback from the evaluation process should lead to corrective actions if necessary. These actions might include, for example, a change in the information system development or procurement strategy, or a change in the resources that are given to the project.

Saarinen [10] noted that evaluating the success of an IS implementation should consider at least two dimensions: the process and the product success. Evaluating the conduct of the IS development process would facilitate the learning for future projects. The product success includes both the IS functionality and the realization of the expected benefits from the IS investment. Hallikainen Heikkilä, Peffers Saarinen, and Wijnhoven, reference [11] puts it that to learn conducting evaluation and managing information system projects more effectively, the perceived success of the evaluation process itself can be measured in terms of: evaluation efficiency, precision, and effectiveness. Evaluation efficiency can be divided into efficiency of evaluation process and cost of evaluation. Evaluation precision can be further divided into satisfaction with evaluation criteria and methods used; and satisfaction with contents, usability and reliability of information produced by evaluation. Finally, evaluation effectiveness can be divided into usefulness of the results of evaluation when making decisions concerning this particular project; and evaluation supporting in aligning 
information technology and business functions.

\section{Conclusions}

Our proposed framework is useful in describing a concept for information systems management and development. Any information system project can neatly be matched into our proposed framework. The primary advantages of our framework are highlighted as follows:

First, the information development process can be better understood by project participants. Better understanding of other participant's perspective of the development process results in improved communications amongst project members along with users. The communication gap has been most significant cause of system failures. Second, our framework views the entire development process as an integrated entity. It integrates different views and thus reduces the task of duplication. Thirdly, our proposed framework sharpens the idea of how the information requirements can be mapped into the strategic goal for the information systems in an organization. It also provides a mapping between users and actors (developers). This mapping is significant especially for prototyping approach.

Finally, our framework accommodates both top-down view and the bottom-up view of the systems management and development activities. Typically, the management process in isolation starts with an activity with by a manager. Activities performed by the manager must be mapped into activities by the actors followed by activities by the users. This transitive specialization corresponds to top-down view for systems development. On the contrary, the development process starts with the activities performed by the users which must be triggered by the users' requirements. These activities are mapped into activities by actors and finally activities by manger. This specialization corresponds to a bottom-up view for systems development. The conventional SDLC phases is however, sharpened by the incorporation of clear cut roles assigned to users during the life cycle of an IS product.

\section{REFERENCES}

[1] H. Barki, S. Rivard and J. Talbot, "Toward an Assess- ment of Software Development Risk," Journal of Management Information Systems, Vol. 10, No. 2, 1993, pp. 203-225.

[2] P. Barrow and P. Mayhew, "Investigating Principles of Stakeholder Evaluation in a Modern IS Development Approach,” The Journal of Systems and Software, Vol. 52, No. 2-3, 2000, pp. 95-103.

[3] G. B. Davis, "Strategies for Information Requirements Determination, IBM,” Systems Journal, Vol. 21, No. 1, 1982, pp. 4-31.

[4] H. Kivijärvi, "Knowledge Conversion in Organizational Context: A Framework and Experiments," Proceedings of the 37th Hawaii International Conference on System Sciences, USA, 2004, p. 10.

[5] D. Santos and B. L. David, "Justifying Investments in New Technologies,” Journal of Management Information Systems, Vol. 7, No. 4, 1991, pp. 71-90.

[6] P. Hallikainen, H. Kivijärvi and K. Nurmimäki, "Evaluating Strategic IT Investments: An Assessment of Investment Alternatives for a Web Content Management System," Proceedings of the HICSS-35, Big Island, Hawaii, 2002, pp. 2977-2986.

[7] T. Saarinen and A. Vepsalainen, "Procurement Strategies for Information Systems,” Journal of Management Information Systems, Vol. 11, No. 2, 1994, pp. 187-208.

[8] R. Heckman, "Managing the IT Procurement Process Information,” Systems Management, Vol. 16, No. 1, 1999, pp. 61-71.

[9] V. Serafeimidis and S. Smithson, "Information Systems Evaluation in Practice: A Case Study of Organizational Change,” Journal of Information Technology, Vol. 15, No. 2, 2000, pp. 93-105.

[10] H. J. Wen and C. Sylla, “A Road Map for the Evaluation of Information Technology Investment,” In: Mahmood and Szewczak, Eds., Measuring Information Technology Investment Payoff: Contemporary Approaches, Idea Group Publishing, Addison Wesldy, New York, 1999, pp. 142-150.

[11] T. Saarinen, "Success of Information Systems. Evaluation of Development Projects and the Choice of Procurement and Implementation Strategies," PhD Dissertation Helsinki School of Economics and Business Administration A-88, 1993. 